\title{
Extraction of vanadium and potassium compounds from the spent vana- dium catalyst from the metallurgical plant
}

\author{
Krzysztof Mazurek \\ Nicolaus Copernicus University, Faculty of Chemistry, Department of Chemical Technology, ul. Gagarina 7, 87-100 Torun, \\ Poland, e-mail: mazur@chem.umk.pl
}

\begin{abstract}
A spent vanadium catalyst, from the plant of metallurgical type, was leached in a sulfuric acid solution to recover vanadium and potassium compounds. The effect of time, temperature, concentration of acid, catalyst particle size and phase ratio was studied. Additionally the concentration of iron, copper, zinc, arsenic and lead compounds was determined. The flow sheet for the proposed process of spent vanadium catalyst leaching is presented.
\end{abstract}

Keywords: sulfuric acid, sulfur oxide, spend vanadium catalysts, leaching, recovery, vanadium, potassium, copper, zinc, arsenic, lead, xrf.

\section{INTRODUCTION}

Vanadium catalysts working in the industrial conditions are deactivated due to the changes occurring in their structure and texture ${ }^{1-14}$. Withdrawn from the process, they pile up on the factory waste dumps or in the concrete silos. These catalysts, subjected to the atmospheric conditions, give the acidic reflux, harmful to the surrounding ecosystems due to the high levels of toxic substances.

The used catalysts constitute the chemically and granulometrically heterogeneous material. The composition of these catalysts strongly depends on the conditions of their usage, the source of sulfur dioxide, as well as the conditions of their storage after withdrawal from the process.

The extent of deactivation is a function of time and conditions of the catalyst use, more rapid deactivation has been reported on for the catalysts used in acid plants at metallurgical plants and those used in the wet catalysis process. This is considered to be due to the metallic impurities such as: $\mathrm{Fe}, \mathrm{Pb}, \mathrm{Zn}, \mathrm{Hg}, \mathrm{Cd}$ and $\mathrm{As}$

The amount of that waste, which could be estimated as close to 3 thousand $\mathrm{Mg}$ in Poland, and their composition indicate the necessity of the research on developing the method of their complex utilization. Up to date, there has been no such method, which would enable the complex utilization of these catalysts.

\section{EXPERIMENTAL SECTION}

\section{Reagents used}

The used vanadium catalyst was sampled from the waste deposit of Copper Smelter in Głogów, Poland, the factory producing the sulfuric acid in the contact process; $\mathrm{H}_{2} \mathrm{SO}_{4}(95 \%$, analytically pure) - POCh Gliwice, Poland.

Before research, the catalyst was milled in the vibrational mill, and divided into the appropriate granulometric fractions with the FRITSH set of sieves. Table 1 presents the composition and Figure 1 presents the exemplary spectrum of the spent vanadium catalyst used to the researches.

\section{Experimental methods}

The effect of time and temperature of leaching, acid

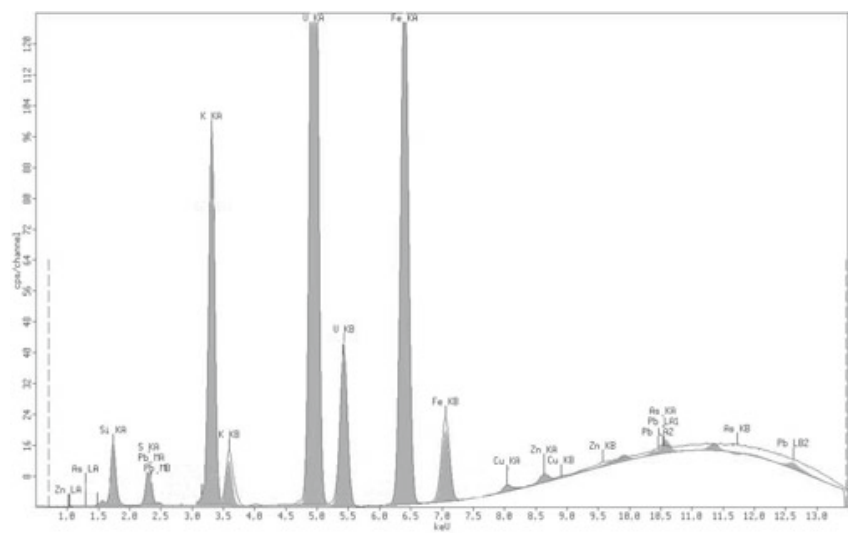

Figure 1. The exemplary spectrum of the spent vanadium catalyst used to the research

concentration, particle size, as well as mass solid to liquid ratio $\left(\mathrm{S}: \mathrm{L}\left(\mathrm{g}: \mathrm{cm}^{3}\right)\right)$ on the efficiency of the recovery of vanadium and potassium compounds from the spent catalyst was investigated. The weighed samples of the vanadium catalyst underwent agitation leaching in a range of different solutions at constant temperature $(+/-0.5$ $\mathrm{K})$. After the required time, the solution was separated by vacuum filtration.

The clear solution was transferred into the flask, diluted with the distilled water and analyzed to determine the concentration of vanadium, potassium, iron, copper, zinc, arsenic and lead compounds.

\section{Analytical methods}

The concentration of all ions in the solutions was determined using the EDXRF method. The analyses were performed with the MiniPal4 PANalytical compact energy dispersive X-ray spectrometer ${ }^{15}$.

\section{RESULTS AND DISCUSSION}

The effect of temperature on the recovery of vanadium, potassium and other ions is presented in Table 2 and Figure 2. Studies were carried out under the following conditions: $10 \% \mathrm{H}_{2} \mathrm{SO}_{4}, \tau=1 \mathrm{~h}, \mathrm{~S}: \mathrm{L}=1: 10$, the catalyst grains $\phi$ : $16-750 \mu \mathrm{m}$.

Table 2 indicates that the recovery of all the studied ions increases with the temperature. Figure 2 shows that there was small significant influence of temperature on the leaching of the vanadium compounds. The lowest re- 


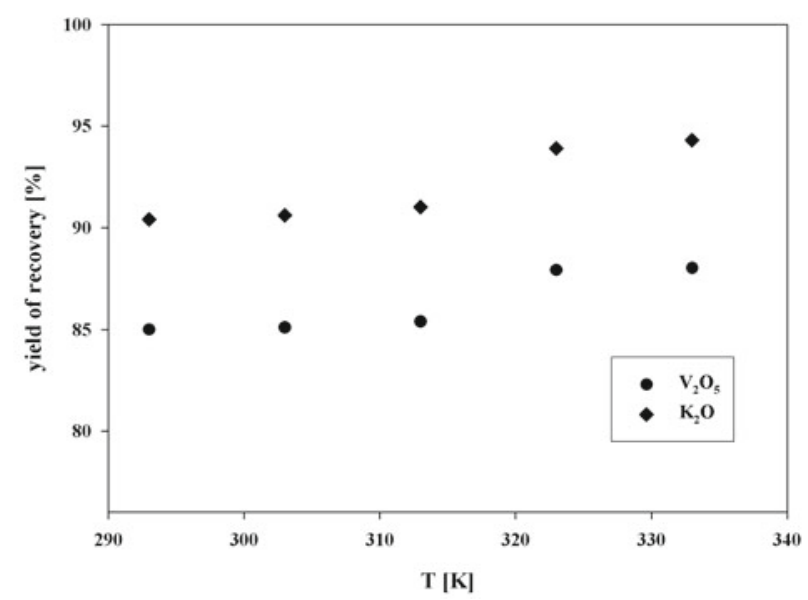

Figure 2. Effect of temperature of leaching process on the efficiency of recovery of vanadium and potassium compounds $\left(\mathrm{C}_{2} \mathrm{SO}_{4}=10 \%, \tau=1 \mathrm{~h}, \mathrm{~S}: \mathrm{L}=1: 10\right.$ (g: $\left.\left.\mathrm{cm}^{3}\right), \phi=160-750 \mu \mathrm{m}\right)$

Table 1. Chemical composition of the spent vanadium catalyst

\begin{tabular}{|l|c|}
\hline compound & content [\%] \\
\hline $\mathrm{SiO}_{2}$ & 60.8 \\
\hline $\mathrm{SO}_{3}$ & 14.5 \\
\hline $\mathrm{K}_{2} \mathrm{O}$ & 8.57 \\
\hline $\mathrm{V}_{2} \mathrm{O}_{5}$ & 5.44 \\
\hline $\mathrm{Fe}_{2} \mathrm{O}_{3}$ & 0.91 \\
\hline $\mathrm{CuO}$ & 0.02 \\
\hline $\mathrm{ZnO}$ & 0.01 \\
\hline $\mathrm{As}_{2} \mathrm{O}_{3}$ & 0.01 \\
\hline $\mathrm{PbO}$ & 0.01 \\
\hline
\end{tabular}

covery ratio of vanadium compounds $(85 \%)$ was achieved for the temperature $293 \mathrm{~K}$, and the highest $88 \%$ for 323 K. Further increase of the temperature doesn't improve of the recovery ratio. Literature reports clearly indicate that the temperature of leaching is not very important for leaching the vanadium compounds in the acidic solutions ${ }^{\mathbf{8}-14}$. Figure 2 indicates that the recovery of potassium compounds increase systematically with the temperature. The highest recovery ratio of $\mathrm{K}_{2} \mathrm{O}(94 \%)$ was achieved for the temperature $333 \mathrm{~K}$. The obtained results reveal that to the solution undergoes also significant amounts of iron compounds. In the temperature $333 \mathrm{~K}$ one liter of post - leaching solution contains more than $0.5 \mathrm{~g}$ of iron(III) oxide. The concentrations of other compounds amounts a few ppm.

The second step of the research included the effect of time on the recovery of the studied compounds. Studies were carried out under the following conditions: $10 \%$ $\mathrm{H}_{2} \mathrm{SO}_{4}, \mathrm{~T}=293 \mathrm{~K}, \mathrm{~S}: \mathrm{L}=1: 10$, the catalyst grains $\phi: 160-750 \mu \mathrm{m}$.
Table 3 and Figure 3 shows that there was small significant influence of time on the leaching of the vanadium and potassium compounds. The highest increase vanadium recovery is obtained by increasing time of leaching from 0.5 to $4 \mathrm{~h}$. For the leaching process of potassium compounds, similar dependencies were observed. The presented data indicate that the time of the process has significant effects in the case of iron, zinc and lead compounds. In the case of iron compounds, increasing the time interval of leaching from 0.5 to $8 \mathrm{~h}$ causes an increase of the obtained concentration of $0.1 \mathrm{~g} / \mathrm{dm}^{3}$. In the case of zinc and lead compounds $-0.003 \mathrm{~g} / \mathrm{dm}^{3}$.

The results of the analyses of solutions, revealing the effect of acid concentration in the leaching solution on the recovery ratio of studied compounds are presented in Table 4 and Figure 4. The leaching was performed at the temperature of $323 \mathrm{~K}$ and time $4 \mathrm{~h}$, ratio $\mathrm{S}: \mathrm{L}=$ $1: 10$, for the catalyst fraction $\phi=160-750 \mu \mathrm{m}$.

Acid concentration has the decreasing effect on the yield of vanadium recovery with an increase in acid concentration from 5 to $40 \%$ decreasing yield by $\sim 4 \%$. For comparison, for potassium the increase was $\sim 3 \%$. For the leaching process of iron and zinc compounds, similar dependencies as for vanadium were observed. With the increasing acid concentration the iron compounds concentration was decreasing from 0.540 to $0.513 \mathrm{~g} / \mathrm{dm}^{3}$.

Table 5 and Figure 5 present the results of the next step focusing on the effect of catalyst granulation on the amount of eluted compounds. The leaching process was performed with a $5 \%$ solution of sulfuric acid, time $4 \mathrm{~h}$, temperature $323 \mathrm{~K}$ and ratio $\mathrm{S}: \mathrm{L}=1: 10$.

Figure 5 shows that the yield of vanadium and potas-

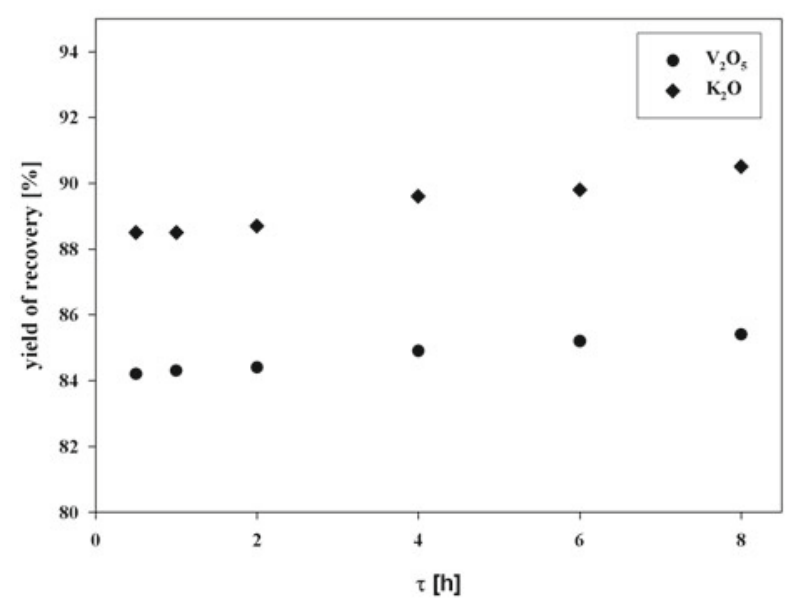

Figure 3. Effect of leaching time on the efficiency of recovery of vanadium and potassium compounds $\left(\mathrm{C}_{2} \mathrm{SO}_{4}=\right.$ $10 \%, \mathrm{~T}=293 \mathrm{~K}, \mathrm{~S}: \mathrm{L}=1: 10\left(\mathrm{~g}: \mathrm{cm}^{3}\right), \phi=160-750$ $\mu \mathrm{m})$

Table 2. Effect of the leaching temperature on the concentration of the studied compounds in post - leaching solution $\left(\mathrm{CH}_{2} \mathrm{SO}_{4}=\right.$ $\left.10 \%, \tau=1 \mathrm{~h}, \mathrm{~S}: \mathrm{L}=1: 10\left(\mathrm{~g}: \mathrm{cm}^{3}\right), \phi=160-750 \mu \mathrm{m}\right)$

\begin{tabular}{|l|c|c|c|c|c|c|c|}
\hline \multirow{2}{*}{$T[K]$} & \multicolumn{7}{|c|}{$\mathrm{c}\left[\mathrm{g} / \mathrm{dm}^{3}\right]$} \\
\cline { 2 - 8 } & $\mathrm{V}_{2} \mathrm{O}_{5}$ & $\mathrm{~K}_{2} \mathrm{O}$ & $\mathrm{Fe}_{2} \mathrm{O}_{3}$ & $\mathrm{CuO}$ & $\mathrm{ZnO}$ & $\mathrm{As}_{2} \mathrm{O}_{3}$ & $\mathrm{PbO}$ \\
\hline 293 & 4.626 & 7.798 & 0.417 & 0.001 & 0.001 & 0.007 & 0.003 \\
\hline 303 & 4.627 & 7.723 & 0.421 & 0.002 & 0.003 & 0.007 & 0.003 \\
\hline 313 & 4.640 & 7.759 & 0.439 & 0.002 & 0.004 & 0.007 & 0.004 \\
\hline 323 & 4.778 & 8.054 & 0.494 & 0.002 & 0.004 & 0.008 & 0.004 \\
\hline 333 & 4.779 & 8.088 & 0.528 & 0.002 & 0.004 & 0.008 & 0.005 \\
\hline
\end{tabular}


Table 3. Effect of leaching time on the concentration of the studied compounds in post - leaching solution $\left(\mathrm{CH}_{2} \mathrm{SO}_{4}=10 \%\right.$, $\left.\mathrm{T}=293 \mathrm{~K}, \mathrm{~S}: \mathrm{L}=1: 10\left(\mathrm{~g}: \mathrm{cm}^{3}\right), \phi=160-750 \mu \mathrm{m}\right)$

\begin{tabular}{|l|c|c|c|c|c|c|c|}
\hline \multirow{2}{*}{$\tau[\mathrm{h}]$} & \multicolumn{7}{|c|}{$\mathrm{c}\left[\mathrm{g} / \mathrm{dm}{ }^{3}\right]$} \\
\cline { 2 - 9 } & $\mathrm{V}_{2} \mathrm{O}_{5}$ & $\mathrm{~K}_{2} \mathrm{O}$ & $\mathrm{Fe}_{2} \mathrm{O}_{3}$ & $\mathrm{CuO}$ & $\mathrm{ZnO}$ & $\mathrm{As}_{2} \mathrm{O}_{3}$ & $\mathrm{PbO}$ \\
\hline 0.5 & 4.580 & 7.589 & 0.410 & 0.001 & 0.001 & 0.006 & 0.002 \\
\hline 1.0 & 4.587 & 7.590 & 0.412 & 0.001 & 0.002 & 0.007 & 0.003 \\
\hline 2.0 & 4.589 & 7.606 & 0.425 & 0.001 & 0.002 & 0.007 & 0.003 \\
\hline 4.0 & 4.621 & 7.680 & 0.435 & 0.001 & 0.003 & 0.007 & 0.003 \\
\hline 6.0 & 4.637 & 7.699 & 0.441 & 0.002 & 0.004 & 0.008 & 0.004 \\
\hline 8.0 & 4.644 & 7.758 & 0.513 & 0.002 & 0.004 & 0.008 & 0.005 \\
\hline
\end{tabular}

Table 4. Effect of sulfuric acid concentration on the concentration of the studied compounds in post - leaching solution $\left(\tau=4 \mathrm{~h}, \mathrm{~T}=323 \mathrm{~K}, \mathrm{~S}: \mathrm{L}=1: 10\left(\mathrm{~g}: \mathrm{cm}^{3}\right), \phi=160-750 \mu \mathrm{m}\right)$

\begin{tabular}{|l|c|c|c|c|c|c|c|}
\hline \multirow{2}{*}{$\mathrm{C}[\%]$} & \multicolumn{7}{|c|}{$\mathrm{c}\left[\mathrm{g} / \mathrm{dm}^{3}\right]$} \\
\cline { 2 - 9 } & $\mathrm{V}_{2} \mathrm{O}_{5}$ & $\mathrm{~K}_{2} \mathrm{O}$ & $\mathrm{Fe}_{2} \mathrm{O}_{3}$ & $\mathrm{CuO}$ & $\mathrm{ZnO}$ & $\mathrm{As}_{2} \mathrm{O}_{3}$ & $\mathrm{PbO}$ \\
\hline 5 & 4.787 & 7.951 & 0.540 & 0.001 & 0.005 & 0.005 & 0.002 \\
\hline 10 & 4.779 & 8.031 & 0.533 & 0.001 & 0.004 & 0.007 & 0.002 \\
\hline 20 & 4.665 & 8.060 & 0.525 & 0.001 & 0.004 & 0.007 & 0.002 \\
\hline 30 & 4.639 & 8.066 & 0.523 & 0.001 & 0.003 & 0.007 & 0.001 \\
\hline 40 & 4.567 & 8.178 & 0.513 & 0.001 & 0.001 & 0.007 & 0.001 \\
\hline
\end{tabular}

Table 5. Effect of catalyst particle size on the concentration of the studied compounds in post - leaching solution $\left(\mathrm{CH}_{2} \mathrm{SO}_{4}=5 \%\right.$, $\left.\tau=4 \mathrm{~h}, \mathrm{~T}=323 \mathrm{~K}, \mathrm{~S}: \mathrm{L}=1: 10\left(\mathrm{~g}: \mathrm{cm}^{3}\right)\right)$

\begin{tabular}{|l|c|c|c|c|c|c|c|}
\hline \multirow{2}{*}{$\phi[\mu \mathrm{m}]$} & \multicolumn{7}{|c|}{$\mathrm{c}\left[\mathrm{g} / \mathrm{dm}^{3}\right]$} \\
\cline { 2 - 9 } & $\mathrm{V}_{2} \mathrm{O}_{5}$ & $\mathrm{~K}_{2} \mathrm{O}$ & $\mathrm{Fe}_{2} \mathrm{O}_{3}$ & $\mathrm{CuO}$ & $\mathrm{ZnO}$ & $\mathrm{As}_{2} \mathrm{O}_{3}$ & $\mathrm{PbO}$ \\
\hline$>1500$ & 4.645 & 7.904 & 0.468 & 0.001 & 0.005 & 0.005 & 0.001 \\
\hline $750-1500$ & 4.762 & 7.926 & 0.525 & 0.002 & 0.005 & 0.005 & 0.001 \\
\hline $160-750$ & 4.790 & 7.960 & 0.547 & 0.001 & 0.005 & 0.005 & 0.002 \\
\hline $88-160$ & 4.787 & 7.960 & 0.572 & 0.001 & 0.005 & 0.005 & 0.002 \\
\hline$<88$ & 4.786 & 7.957 & 0.598 & 0.001 & 0.005 & 0.005 & 0.002 \\
\hline
\end{tabular}

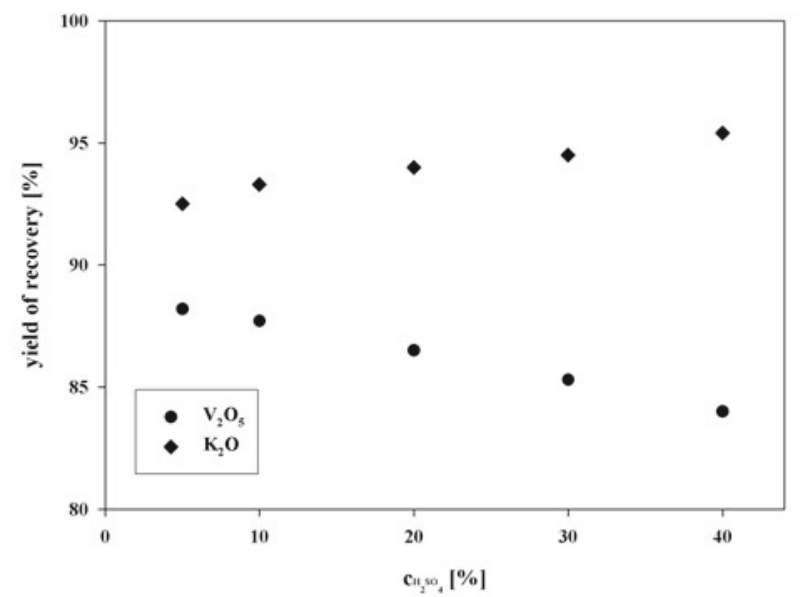

Figure 4. Effect of sulfuric acid concentration on the efficiency of recovery of vanadium and potassium compounds $\left(\tau=4 \mathrm{~h}, \mathrm{~T}=323 \mathrm{~K}, \mathrm{~S}: \mathrm{L}=1: 10\left(\mathrm{~g}: \mathrm{cm}^{3}\right), \phi=160-750\right.$ $\mu \mathrm{m})$

sium recovery in post-leaching solutions increases with decreasing the catalyst particle size. The lowest vanadium and potassium recovery was obtained for the largest particle size fraction. Decreasing the particle size less than $750 \mu \mathrm{m}$ causes a significant increase in vanadium and potassium dissolution. Further size reduction does not lead to a significant increase of the yield of recovery of vanadium or potassium but greatly increases the iron

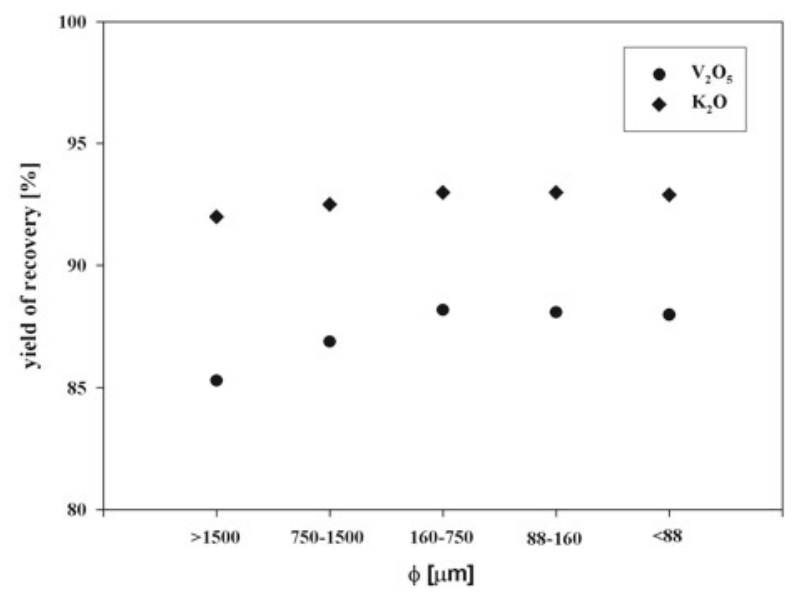

Figure 5. Effect of catalyst particle size on the efficiency of leaching process of the vanadium and potassium compounds $\left(\mathrm{C}_{2} \mathrm{SO}_{4}=5 \%, \tau=4 \mathrm{~h}, \mathrm{~T}=323 \mathrm{~K}, \mathrm{~S}: \mathrm{L}\right.$ $\left.=1: 10\left(\mathrm{~g}: \mathrm{cm}^{3}\right)\right)$

dissolution. Table 5 shows that there was no significant influence of particle size on the leaching of the copper, zinc, arsenic and lead compounds.

Table 6 and Figure 6 present the data on the effect of S:L ratio on the leaching. Studies were carried out under the following conditions: $5 \% \mathrm{H}_{2} \mathrm{SO}_{4}, \mathrm{~T}=323 \mathrm{~K}$, $\tau=4 \mathrm{~h}$, the catalyst grains $\phi: 160-750 \mu \mathrm{m}$. 
Table 6. Effect of S:L $\left(\mathrm{g}: \mathrm{cm}^{3}\right)$ ratio on the concentration of the studied compounds in post - leaching solution $\left(\mathrm{CH}_{2} \mathrm{SO}_{4}=5 \%\right.$, $\tau=4 \mathrm{~h}, \mathrm{~T}=293 \mathrm{~K},\left(\mathrm{CH}_{2} \mathrm{SO}_{4}=5 \%, \tau=4 \mathrm{~h}, \mathrm{~T}=323 \mathrm{~K}, \phi=160-750 \mu \mathrm{m}\right)$

\begin{tabular}{|c|c|c|c|c|c|c|c|}
\hline \multirow{2}{*}{$\mathrm{S}: \mathrm{L}\left[\mathrm{g}: \mathrm{cm}^{3}\right]$} & \multicolumn{7}{|c|}{$c\left[\mathrm{~g} / \mathrm{dm}^{3}\right]$} \\
\hline & $\mathrm{V}_{2} \mathrm{O}_{5}$ & $\mathrm{~K}_{2} \mathrm{O}$ & $\mathrm{Fe}_{2} \mathrm{O}_{3}$ & $\mathrm{CuO}$ & $\mathrm{ZnO}$ & $\mathrm{As}_{2} \mathrm{O}_{3}$ & $\mathrm{PbO}$ \\
\hline $1 / 2.5$ & 11.886 & 29.202 & 1.663 & 0.006 & 0.013 & 0.019 & 0.007 \\
\hline $1 / 5$ & 8.593 & 15.640 & 0.916 & 0.003 & 0.008 & 0.008 & 0.005 \\
\hline $1 / 10$ & 4.792 & 7.949 & 0.545 & 0.001 & 0.004 & 0.005 & 0.002 \\
\hline $1 / 15$ & 3.185 & 5.358 & 0.342 & 0.001 & 0.003 & 0.004 & 0.002 \\
\hline $1 / 20$ & 2.465 & 4.162 & 0.232 & 0.000 & 0.002 & 0.004 & 0.001 \\
\hline
\end{tabular}

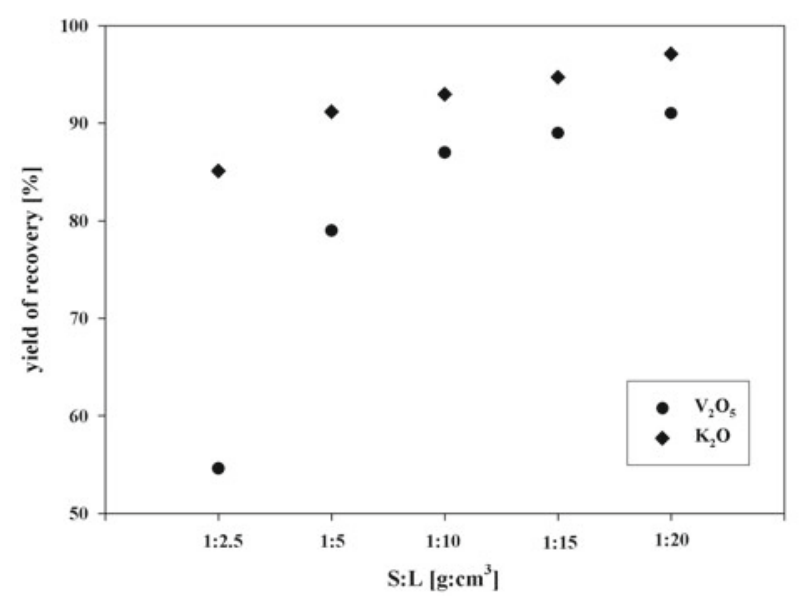

Figure 6. The effect of the ratio of the mass of catalyst to the volume of the leaching factor $\left(\mathrm{S}: \mathrm{L}\left(\mathrm{g}: \mathrm{cm}^{3}\right)\right)$ on the leaching efficacy $\left(\mathrm{CH}_{2} \mathrm{SO}_{4}=5 \%, \tau=4 \mathrm{~h}, \mathrm{~T}=293\right.$ $\mathrm{K},\left(\mathrm{C}_{2} \mathrm{SO}_{4}=5 \%, \tau=4 \mathrm{~h}, \mathrm{~T}=323 \mathrm{~K}, \phi=160-750\right.$ $\mu \mathrm{m})$

For the S:L ratio of 1:2.5 the extent of leaching for vanadium and potassium compounds was 55 and $85 \%$, respectively. A much higher rate of dissolution is achieved with a higher S:L ratio (1:20) with recoveries of 91, 97\%. An increase of the S:L ratio affects the degree of leaching for both vanadium and potassium compounds.

A conceptual process flow sheet for the complex method of recovery of compounds from spent catalyst using sulfuric acid solution leaching and production new catalyst is presented in Figure 7. The new catalyst will be produced using the wet technique based on the post - leaching solution. To the post - leaching solution in the addition to the active phase components undergoes significant amounts of iron compounds. These compounds must be removed from the post - leaching solution before its use for the production of new catalyst ${ }^{4}$. The results of the research implies clearly that with increasing solution $\mathrm{pH}$, the yield of recovery of iron(III) oxide is decreased due to precipitation of ferric oxide phases ${ }^{8}$. Changing the $\mathrm{pH}$ of the leaching solutions can be performed by an addition of the required amount of potassium hydroxide to the leaching solution. Because the recovery ratio of iron compounds doesn't exceed $50 \%$, recovered silica contains also a significant amounts of iron compounds (3-6\%) and for this reason can't be used to production of new catalyst ${ }^{4}$. The concentrations of the other studied ions in the post - leaching solution, especially arsenic, at the ratio S:L higher than 1:10 don't exceed the European Standards. Therefore, after the possible precipitation of vanadium and potassium compounds, the solution can be discharged into a wastewater.

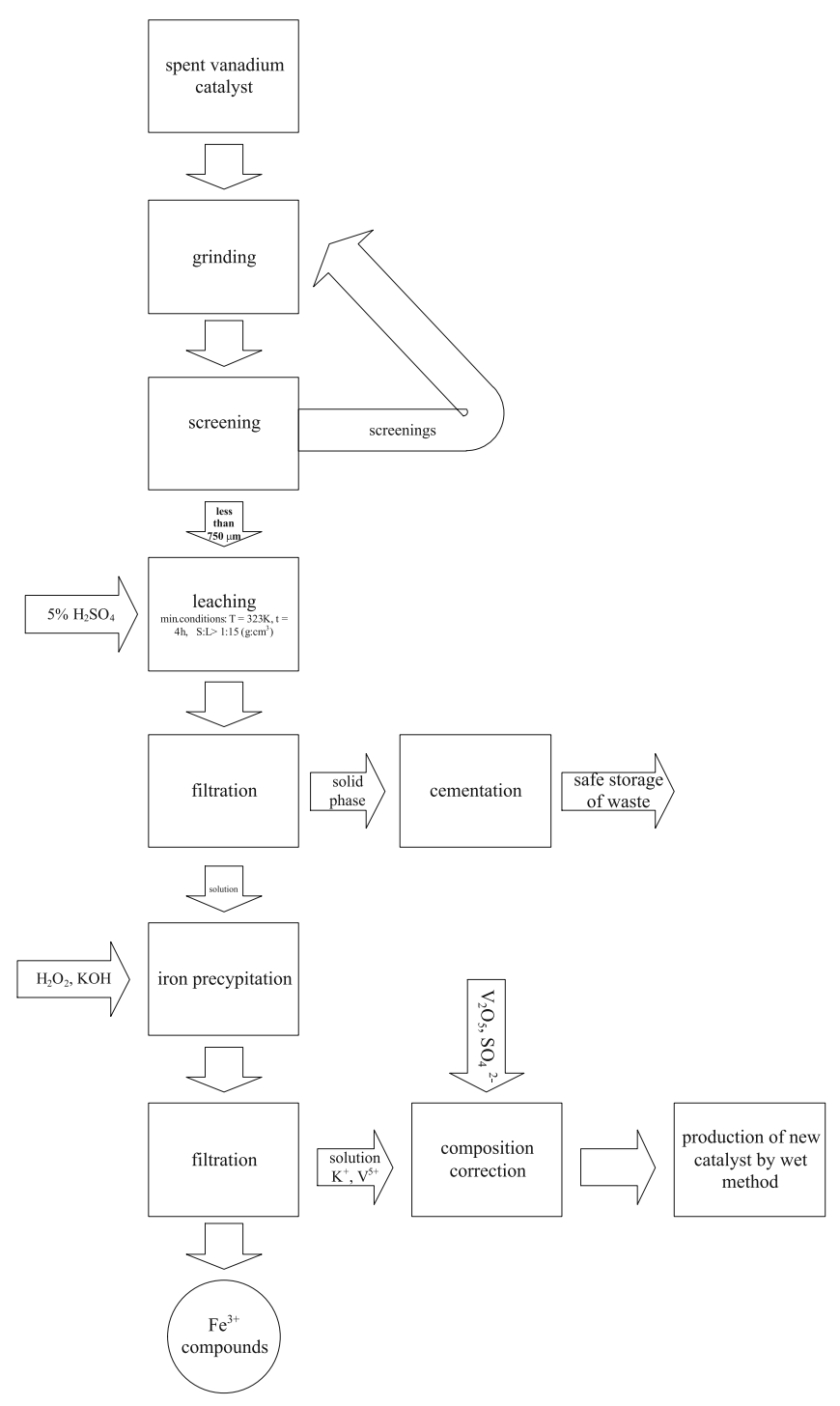

Figure 7. A conceptual process flow sheet for the production of new vanadium catalyst using wet method

\section{SUMMARY}

Sulfuric acid, can be used for the recovery of valuable components from used vanadium catalyst. The obtained yields for compounds occurring in the active phase of the catalyst (vanadium and potassium) are satisfactory from the technological point of view. Maximum degree of vanadium and potassium recovery from the used vanadium catalyst (91 and 97\%) was achieved for the extraction conditions: $5 \% \mathrm{H}_{2} \mathrm{SO}_{4}, \mathrm{~T}=323 \mathrm{~K}, \tau=4 \mathrm{~h}$, $\mathrm{S}: \mathrm{L}=1: 20, \phi$ : less than $750 \mu \mathrm{m}$.

\section{ACKNOWLEDGEMENT}

The project was funded by the National Science Centre. 


\section{LITERATURE CITED}

1. Grzesiak, P. (2006). Utilization of industrial waste from sulfuric acid production processes. Przem. Chem. 8-9, 10151019 (in Polish).

2. Grzesiak, P. (2005). Vanadium catalysts for the oxidation of $\mathrm{SO}_{2}$. Poznań, Poland: WN IOR (in Polish).

3. Mazurek, K., Białowicz, K. \& Trypuć, M. (2010). Extraction of vanadium compounds from the used vanadium catalyst with the potassium hydroxide solution. Polish J. Chem. Technol. 1(12), 23-28, DOI: 10.2478/v10026-010-0005-2.

4. Grobela, M. \& Grzesiak, P. (2007). The influence of iron compounds in the sulfuric acid catalyst on the $\mathrm{SO}_{2}$ oxidation process. Polish J. Chem. Technol. 1(9), 2-6, DOI: 10.2478/ v10026-007-0002-2.

5. Grzesiak, P., Grobela, M. \& Motała, M. (2007). The influence of the catalyst worktime on $\mathrm{SO}_{2}$ emission quantity from the sulfuric acid system and the catalyst waste material. Polish J. Chem. Technol. 3(9), 134-137, DOI: 10.2478/v10026007-0073-0.

6. Trypuć, M., Mazurek, K., Kiełkowska, U. \& Drużyński, S. (2007). Utilization of used contact masses from the oxidation state of sulfur(IV) oxide to sulfur(VI) oxide. Pol. J. Chem. Technol. 9(3), 26-28, DOI: 10.2478/v10026-007-0047-2.

7. Mazurek, K., Trypuć, M., Białowicz, K. \& Drużyński, S. (2008). The influence of leaching solution $\mathrm{pH}$ and addition of peroxide hydrogen on the recovery of some components from the used vanadium catalyst with urea solutions. Pol. J. Chem. Technol. 10(4), 34-36, DOI: 10.2478/v10026-008-0044-0.

8. Mazurek, K., Białowicz, K. \& Trypuć, M. (2010). Recovery of vanadium, potassium and iron from a spent catalyst using urea solution. Hydrometallurgy 103, 19-24, DOI: 10.1016/j. hydromet.2010.02.008.

9. Khorfan, S., Wahoud, A. \& Reda, Y. (2001). Recovery of vanadium pentaoxide from spent catalyst used in the manufacture of sulphuric acid. Periodica Polythechnica Ser. Chem. Eng. 45(2), 131-137.

10. Mohanty, J., Rath, P.C., Bhattacharya, I.N. \& Paramguru, R.K. (2011). The recovery of vanadium from spent catalyst: a case study. Mineral Processing and Extractive Metallurgy 120, 56-60, DOI: 10.1179/037195510X12772935654909.

11. Zeng, L. \& Cheng, C.Y. (2009). A literature review of the recovery of molybdenum and vanadium from spent hydrodesulphurization catalysts. Part I: metallurgical processes. Hydrometallurgy 98, 1-9, DOI: 10.1016/j.hydromet.2009.03.010.

12. Zeng, L. \& Cheng, C.Y. (2009). A literature review of the recovery of molybdenum and vanadium from spent hydrodesulphurization catalysts. Part II: separation and purification. Hydrometallurgy 98, 10-20, DOI:10.1016/j.hydromet.2009.03.012.

13. Magnani, J.L., Kachan, G.C. \& Ferreira, N.L. (2000). Vanadium recovery by leaching in spent catalyst for sulfuric acid production. Rev. Ciencia Technol. 8, 85-90.

14. Lozano, L.J. \& Juan, D. (2001). Leaching of vanadium from spent sulphuric acid catalysts. Miner. Eng. 5, 543-546, DOI:10.1016/S0892-6875(01)00042-5.

15. Brouwer, P. (2006). Theory of XRF. Almelo, Netherlands: Panalytical. 